\title{
Bactericidal Effect and Anti-Inflammatory Activity of Cassia garettiana Heartwood Extract
}

\author{
Sumalee Panthong $\mathbb{D}^{1,2}$ Arunporn Itharat $\mathbb{D}^{1,2}$ Suchada Naknarin, ${ }^{3}$ \\ Pranporn Kuropakornpong, ${ }^{3}$ Buncha Ooraikul, ${ }^{4}$ and Intouch Sakpakdeejaroen ${ }^{1}$ \\ ${ }^{1}$ Department of Applied Thai Traditional Medicine, Faculty of Medicine, Thammasat University, Khlong Nueng, \\ Pathumthani 12120, Thailand \\ ${ }^{2}$ Centre of Excellence in Applied Thai Traditional Medicine Research (CEATMR), Thammasat University, Khlong Nueng, \\ Pathumthani 12120, Thailand \\ ${ }^{3}$ Faculty of Medicine, Thammasat University, Khlong Nueng, Pathumthani 12120, Thailand \\ ${ }^{4}$ Bualuang ASEAN Chair Professorship, Thammasat University, Khlong Nueng, Pathumthani 12120, Thailand
}

Correspondence should be addressed to Sumalee Panthong; psumalee@tu.ac.th

Received 7 April 2020; Revised 17 June 2020; Accepted 24 June 2020; Published 13 July 2020

Academic Editor: Khoa Nguyen

Copyright (c) 2020 Sumalee Panthong et al. This is an open access article distributed under the Creative Commons Attribution License, which permits unrestricted use, distribution, and reproduction in any medium, provided the original work is properly cited.

Natural products are used as alternative drugs in traditional medicine to treat infection and inflammation and relieve pain. Heartwood of Cassia garettiana Craib has been investigated as an ingredient in Thai traditional medicine for anti-HIV protease, but there is no report on its antibacterial and anti-inflammatory activities. The objectives of this study were to investigate the antiinflammatory and antibacterial activities, time-kill profile, and main active constituents of an ethanolic extract of C. garettiana heartwood. The study followed the generally accepted experimental design. All tests were investigated in triplicate. The heartwood of C. garettiana was extracted by maceration with $95 \% \mathrm{EtOH}$. The antibacterial activity of the extract and its chemical constituents were determined by their MIC values using resazurin as an indicator. Time-kill profile was determined at $0,2,4,6,8,10,12$, and $24 \mathrm{hrs}$ and expressed as $\log \mathrm{CFU} / \mathrm{mL}$. The anti-inflammatory activity of the extract and its chemical components was investigated by their inhibiting effect on IL- 6 and TNF- $\alpha$ production by ELISA. The ethanolic extract was analyzed for its chemical constituents by HPLC technique. The ethanolic extract showed both dose- and time-dependent bactericidal effects against Staphylococcus aureus, methicillin-resistance Staphylococcus aureus, Staphylococcus epidermidis, Escherichia coli, Pseudomonas aeruginosa, Salmonella Typhi, Salmonella Typhimurium, Klebsiella pneumoniae, and Shigella dysenteriae with MIC values of 312.5, 312.5, $312.5,1,250,2,500,625,625,2,500$, and $625 \mu \mathrm{g} / \mathrm{mL}$, respectively. It showed an inhibiting effect on IL-6 production at concentrations of 12.5 to $100 \mu \mathrm{g} / \mathrm{mL}$. The main active chemical constituent of C. garettiana was piceatannol that showed antibacterial activity against all test bacteria except $P$. aeruginosa. C. garettiana showed a broad spectrum of antibacterial activity against both Gram-negative and Gram-positive bacteria. Piceatannol and resveratrol from the plant strongly inhibited IL-6 production. Based on these results, we concluded that the ethanolic extract of C. garettiana showed both an antibacterial activity and inhibition of IL6. Piceatannol is the active constituent of the extract and showed anti-inflammatory and antibacterial activities against Gramnegative and Gram-positive bacteria.

\section{Introduction}

Infection is an invasion of pathogens such as viruses, bacteria, fungi, and protozoa in body tissues [1]. The immune system response to these pathogens is to kill them and protect the host from the microorganisms. The response of immune system leads to acute inflammation of the tissue to remove the pathogen and heal cell damage. Unfortunately, acute inflammation leads to the development of chronic inflammation when it cannot be controlled [2]. Normally, antibiotics are used as first-line drugs to treat bacterial infections [3]. However, antibiotic-resistant bacteria are 
increasing globally, so new antibacterial agents or antibiotics need to be developed to treat these infections, for example, tigecycline, doripenem, and plant extracts [4-6]. Cassia garettiana Craib, a herb belonging to the Caesalpiniaceae family, has been used to treat bacterial infections and inflammation and reduce body heat in Thai traditional medicine. Ethanolic extract of C. garettiana has been shown to inhibit HIV-1 protease [7]. The heartwood of C. garettiana contained piceatannol, chrysophanol, oxyresveratrol, resveratrol, emodin, aloe-emodin, and rhein [8]. Previous studies have shown the antibacterial and anti-inflammatory activities of these compounds [9-11]. However, the antibacterial and anti-inflammatory activities of the ethanolic extract of C. garettiana has not yet been explored. Moreover, the contents of the main active constituents have not been investigated. This study was designed to investigate the antibacterial activity, time-kill profile, anti-inflammatory activity, main active constituents of the ethanolic extract of C. garettiana, and effect of chemical constituents of the extract on antibacterial and anti-inflammatory activities.

\section{Materials and Methods}

2.1. Plant Materials. The heartwood of C. garettiana was collected by a Thai traditional doctor from Samutsakorn Province, Thailand, in February 2019. It was identified by comparison with authentic voucher specimens that were kept in the herbarium of Southern Centre of Thai Medicinal Plants, Faculty of Pharmaceutical Sciences, Prince of Songkla University, Songkhla Province, Thailand. The voucher specimen number was SKP034030701.

2.2. Chemical and Reagents. Nutrient agar and Mueller Hinton broth were purchased from Difco, USA. Norfloxacin, vancomycin, piceatannol, and resveratrol were purchased from TCI, Japan. Sodium chloride was obtained from Emsure, USA. Resazurin sodium salt, lipopolysaccharide (LPS), and MTT were purchased from Sigma Aldrich, Germany. Acetonitrile, acetic acid, and dimethyl sulfoxide were purchased from RCI Lab Scan, Thailand. Dulbecco's modified Eagle's medium, fetal bovine serum (FBS), and penicillin/streptomycin were purchased from Gibco, USA. IL-6 and TNF- $\alpha$ ELISA kits were purchased from ImmunoTools, Germany.

\subsection{Antibacterial Activity}

2.3.1. Microorganisms Testing. A total of nine bacteria species were obtained from The National Institute of Health of Thailand, including three species of Gram-positive bacteria: Staphylococcus aureus ATCC25923, methicillin-resistance Staphylococcus aureus (MRSA) DMST20651, and Staphylococcus epidermidis ATCC12228 and six species of Gram-negative bacteria: Escherichia coli ATCC25922, Pseudomonas aeruginosa ATCC9027, Salmonella Typhi DMST22842, Salmonella Typhimurium ATCC13311, Klebsiella pneumoniae ATCC70603, and Shigella dysenteriae DMST15111.
2.3.2. Preparation of Extract. The heartwood of C. garettiana was washed and dried at $50^{\circ} \mathrm{C}$ for four days, then ground into powder by a grinding machine (DXFILL Model: DXM1000), and macerated with $95 \% \mathrm{v} / \mathrm{v}$ ethanol for three days at room temperature. The mixture was filtered through Whatman no. 1 paper, evaporated, and dried by a lyophilizer (Labconco Model: FreeZone2.5). The dried ethanolic extract was weighed and stored at $-20^{\circ} \mathrm{C}$ until use.

\subsubsection{Determinations of Minimal Inhibitory Concentration} (MIC) and Minimal Bactericidal Concentration (MBC). The MIC value of $C$. garettiana ethanolic extract and its chemical constituents, including piceatannol and resveratrol, were determined using the microtiter plate-based antibacterial assay describe by Sarker et al. [12]. Briefly, the extract was dissolved in ethanol at a concentration of $500 \mathrm{mg} / \mathrm{mL}$ and diluted with Muller Hinton broth to a maximum concentration of $10 \mathrm{mg} / \mathrm{mL}$ followed by twofold serial dilutions to obtain concentrations ranging between 0.078 and $10 \mathrm{mg} / \mathrm{mL}$ in Muller Hinton broth, while piceatannol and resveratrol were prepared at $100 \mathrm{mg} / \mathrm{mL}$ in ethanol and diluted in serial twofold dilutions $(0.0156$ to $2 \mathrm{mg} / \mathrm{mL})$. These solutions were transferred to 96 -well plates ( $50 \mu \mathrm{L} /$ well) in triplicate. Bacteria that had been grown at $37^{\circ} \mathrm{C}$ for $24 \mathrm{~h}$ were transferred into Muller Hinton broth and adjusted to $0.5 \mathrm{McF}$ arland by McFarland densitometer. Bacteria suspension ( $50 \mu \mathrm{L} /$ well) was transferred into each well of the 96-well plate and incubated at $37^{\circ} \mathrm{C}$ for $20 \mathrm{~h}$. The final concentration ranges of C. garettiana extract after inoculation were 0.039 to $5 \mathrm{mg} / \mathrm{mL}$, while the final concentration ranges of piceatannol and resveratrol were 0.0078 to $1 \mathrm{mg} / \mathrm{mL}$. The maximum final concentration of ethanol was $1 \% \mathrm{v} / \mathrm{v}$ per well. After the incubation, resazurin sodium salt solution $(1 \mathrm{mg} / \mathrm{mL})$ was added into each well $(10 \mu \mathrm{L} /$ well $)$ and incubated continually at $37^{\circ} \mathrm{C}$ for $3 \mathrm{~h}$. The lowest concentration with no change of resazurin color was recorded as MIC value. Subsequently, all concentrations with no change of resazurin color were transferred onto nutrient agar and incubated at $37^{\circ} \mathrm{C}$ for $24 \mathrm{~h}$. The lowest concentration with no growth of bacteria was marked as MBC.

2.3.4. Time-Kill Assay. The time-kill assay was performed using a modified method as previously described [13]. The ethanolic extract was prepared at concentrations equal to the MIC, two times the MIC, and four times the MIC. Each concentration was transferred into a culture tube $(2 \mathrm{~mL} /$ tube). A $0.5 \mathrm{McF}$ arland inoculum was then prepared and added into each tube $(2 \mathrm{~mL} /$ tube $)$ and incubated at $37^{\circ} \mathrm{C}$ in a shaker incubator. The samples were collected at $0,2,4,6,8$, 10,12 , and $24 \mathrm{~h}$ to determine the colony-forming unit (CFU). All samples were performed in triplicate and recorded as mean \pm standard deviation of $\log \mathrm{CFU} / \mathrm{mL}$.

\subsection{Anti-Inflammatory Activity}

2.4.1. Cell Culture and Viability. RAW264.7 macrophage cells were cultured in Dulbecco's modified Eagle's medium with $10 \%$ FBS, $100 \mu / \mathrm{mL}$ of penicillin, and $100 \mu \mathrm{g} / \mathrm{mL}$ of streptomycin. Cells were subcultured every four days. 
2.4.2. Determination of Cell Survival by MTT Assay. RAW264.7 cells were seeded into a 96-well plate with the concentration of $1 \times 10^{5}$ cells/well and incubated at $37^{\circ} \mathrm{C}$ in $5 \% \mathrm{CO}_{2}$ for 24 hours. The medium was subsequently removed and replaced with fresh medium containing various concentrations of $C$. garettiana extract or pure compounds, including piceatannol and resveratrol, and $5 \mathrm{ng} / \mathrm{mL}$ of lipopolysaccharide (LPS). The plate was incubated at $37^{\circ} \mathrm{C}$ in $5 \% \mathrm{CO}_{2}$ for 24 hours. After incubation, supernatant $(100 \mu \mathrm{L} /$ well) was collected to detect IL- 6 and TNF- $\alpha$ production by ELISA. The survival of the cells was determined by MTT assay. The MTT solution $(10 \mu \mathrm{L} /$ well $)$ was added into each well and incubated at $37^{\circ} \mathrm{C}$ in $5 \% \mathrm{CO}_{2}$ for two hours. Supernatants were then removed and replaced with $0.04 \mathrm{M}$ $\mathrm{HCl}$ in isopropanol at $100 \mu \mathrm{L} /$ well. The absorbance of the content was measured at $570 \mathrm{~nm}$ and the result was expressed as mean \pm SEM of the percentage of survival.

2.4.3. Evaluation of TNF- $\alpha$ and IL-6 Production. ELISA kits were used according to the manufacturer's instructions. The supernatant $(100 \mu \mathrm{L} /$ well $)$ was added into the wells that were coated with a specific capture antibody and incubated at room temperature for two hours. The plate was washed five times with wash buffer followed by the addition of the detection antibody $(100 \mu \mathrm{L} /$ well) into each well and incubated for two hours at room temperature. The plate was again washed five times with wash buffer, and then the polyHRP-streptavidin $(100 \mu \mathrm{L} /$ well $)$ was added into each well and incubated for 30 minutes at room temperature. Finally, the plate was again washed five times with wash buffer, and the TMB substrate solution $(100 \mu \mathrm{L} /$ well $)$ was added into each well and further incubated for 30 minutes in the dark at room temperature. The stop solution was added into each well and the optical density of the content was measured at $450 \mathrm{~nm}$. All experiments were performed in triplicate and the results were recorded as mean \pm SEM of TNF- $\alpha$ or IL- 6 production. Prednisolone was used as a positive control.

2.5. Determination of Chemical Constituents in the Ethanolic Extract of C. garettiana by HPLC. Piceatannol and resveratrol contents in the ethanolic extract were analyzed using high-performance liquid chromatography (HPLC) system with ultraviolet-visible (UV-vis) detector and automatic injector. Briefly, the ethanolic extract of C. garettiana $(5 \mathrm{mg} /$ $\mathrm{mL}$ ) was weighed and dissolved with $1 \mathrm{~mL}$ of acetonitrile in a $2 \mathrm{~mL}$ vial. The solution was filtered through $0.45 \mu \mathrm{m}$ filter before injection. The solution $(10 \mu \mathrm{L})$ was injected into HPLC column. Chemical constituents of the extract were separated by the $\mathrm{C} 18$ reverse phase column (Phenomenax Luna $5 \mu$ C18 (2) $100 \mathrm{~A}$ analytical column $250 \times 4.60 \mathrm{~mm} 5$ microns) with a guard column of the same material. The mobile phase gradient elution consisted of $1 \%$ acetic acid in water (A) and acetonitrile (B) using four-stage linear gradient: $0-5 \mathrm{~min}, 90 \% \mathrm{~A}, 5-30 \mathrm{~min}, 60 \% \mathrm{~A}$, and $30-35 \mathrm{~min}$, $90 \% \mathrm{~A}$. The elution was performed at a flow rate of $1 \mathrm{~mL} / \mathrm{min}$ in $35 \mathrm{~min}$ and monitored at $286 \mathrm{~nm}$. The piceatannol and resveratrol peaks in the extract were analyzed in the area under the curve and their amounts were determined using the standard curve. However, the piceatannol and resveratrol peak in the ethanolic extract was confirmed by spiking with standard piceatannol or resveratrol. All experiments were performed in triplicate and presented as mean\pm standard deviation of $\mathrm{mg} / \mathrm{g}$ of crude extract.

2.6. Statistical Analysis. Statistical analysis was performed using ANOVA and Tukey's multiple comparison tests. Statistical significance was indicated when $p$ value $<0.05$.

\section{Results and Discussion}

3.1. Determination of MIC and MBC of C. garettiana Extract. The microtiter plate-based antibacterial assay including resazurin as an indicator was performed to investigate the MIC values of the ethanolic extract against nine species of bacteria. Resazurin that was of a blue color was reduced to resorufin (pink) by active bacteria [14]. The C. garettiana extract that showed no resazurin color change indicated inhibition of all bacterial growth. The MIC values of the extract are shown in Table 1. The extract showed that it could inhibit all Gram-positive and Gram-negative bacteria, which included S. aureus, MRSA, and S. epidermidis with the MIC value of $312.5 \mu \mathrm{g} / \mathrm{mL}$ and the $\mathrm{MBC} / \mathrm{MIC}$ ratios of 2,2 , and 1 , respectively. For Gram-negative bacteria, the extract could kill six species of bacteria with MIC and MBC range of $625-2,500 \mu \mathrm{g} / \mathrm{mL}$. However, Gram-positive bacteria appeared to be more sensitive to C. garettiana extract than Gram-negative bacteria.

Antibiotics commonly used to treat and prevent infections are divided into two categories, that is, bacteriostatic and bactericidal [15]. Antibiotic-resistant bacteria are a global problem, especially multidrug-resistant bacteria [16]. New antibiotics and antibacterial agents that are effective against bacterial infections are being developed to replace the antibiotics that have been reported to cause resistance [5]. Plant extracts and their chemical components, including alkaloid, terpenoid, and coumarin, have been reported to have an antibacterial activity [17]. C. garettiana is a Thai medicinal plant that has been reported to inhibit HIV-1 protease activity [7]. Seven compounds, which include piceatannol, chrysophanol, oxyresveratrol, resveratrol, emodin, aloe-emodin, and rhein, have been isolated from the plant and showed anti-HIV-1 protease activity [8].

In our study, we tested the antibacterial activity of $C$. garettiana extract and its chemical compounds. The extract showed activity against $S$. aureus, MRSA, S. epidermidis, E. coli, $P$. aeruginosa, Salmonella Typhi, Salmonella Typhimurium, S. dysenteriae, and K. pneumoniae with the MBC/ MIC ratio in the range of 1-2. Antibacterial agents are considered bactericidal when they show the MBC/MIC ratio of no more than fourfold [18]. C. garettiana extract showed a bactericidal effect against all test bacteria with the MBC/MIC ratio of less than four.

The antibacterial activity of $C$. garettiana is being reported for the first time. However, other Cassia species such as Cassia fistula and Cassia alata have been reported to have antibacterial activity. The ethanolic and methanolic extract 
of C. fistula flowers inhibited S. aureus, E. coli, S. epidermidis, and $K$. pneumoniae in the MIC range of $5-40 \mathrm{mg} / \mathrm{mL}$ [19]. The acetone extract of the root of C. alata showed a strong inhibition effect against Bacillus cereus with MIC value of $40 \mu \mathrm{g} / \mathrm{mL}$, while the extracts of its leaves and twigs showed moderate antibacterial activity against $B$. cereus, MRSA, and S. aureus with the MIC range of $160-320 \mu \mathrm{g} / \mathrm{mL}$ [20]. Similarly, the ethanolic extract of C. garettiana showed antibacterial activity against MRSA and $S$. aureus with MIC value of $312.5 \mu \mathrm{g} / \mathrm{mL}$. One possibility is that $C$. garettiana may have similar chemical constituents to $C$. alata.

3.2. Time-Kill Assay of C. garettiana Extract against Nine Species of Bacteria. The correlation between the concentration and time of antibacterial activity of C. garettiana extract is shown in Figure 1. The suppression of the growth of $S$. aureus by the extract at $1 \mathrm{X}$ MIC showed a stable timekill curve. Following treatment for 24 hours, the extract could kill $S$. aureus with a reduction of $2 \log 10 \mathrm{CFU} / \mathrm{mL}$ at 2X MIC and 4X MIC. Similarly, the growth of MRSA and Salmonella Typhimurium was inhibited at $1 \mathrm{X}$ MIC and killed at $2 \mathrm{X}$ and $4 \mathrm{X}$ MIC. The ethanolic extract slightly decreased the growth of S. epidermidis at $1 \mathrm{X}$ MIC and $2 \mathrm{X}$ MIC and killed it at $4 \mathrm{X}$ MIC, with a reduction of 1 $\log 10 \mathrm{CFU} / \mathrm{mL}$. The reduction of E. coli, S. dysenteriae, $P$. aeruginosa, Salmonella Typhi, and K. pneumoniae was 1 $\log 10 \mathrm{CFU} / \mathrm{mL}$ when incubated with C. garettiana extract at $1 \mathrm{X}$ MIC, 2X MIC, and 4X MIC for 2 to $10 \mathrm{~h}$, as shown in Figure 1.

Time-kill assessment is used to confirm the antibiotic's mechanism. Bacteriostatic is defined as the reduction of $<3$ $\log 10 \mathrm{CFU} / \mathrm{mL}$, while bactericidal is defined as $\geq 3 \log 10 \mathrm{re}-$ duction in CFU/mL [21]. C. garettiana extract showed a dosedependent bactericidal activity on S. aureus, MRSA, S. epidermidis, and Salmonella Typhimurium. For other bacteria species, the extract showed a time- and dose-dependent bactericidal effect with the reduction of $>3 \log 10$ in CFU/mL. The extract showed a broad-spectrum effect against both Gram-negative and Gram-positive bacteria. Broad-spectrum antibiotics are effective against the two bacterial groups [15]. The effect of broad-spectrum antibiotics is not necessarily confined to identified bacteria species, but they also affect nonpathogenic bacteria such as the host-microbiome [22]. C. garettiana extract showed an inhibiting effect against MRSA, resistant to $\beta$-lactam antibiotics that involve the penicillin-binding proteins. Chemical compounds of the plant include epicatechin gallate and epigallocatechin gallate which affect penicillin-binding protein 3 (PBP3) and inhibit the growth of MRSA [23]. Thus, C. garettiana extract may affect PBP3 and show an antibacterial mechanism similar to epicatechin gallate in green tea.

3.3. Effect of the Ethanolic Extract of C. garettiana on TNF- $\alpha$ and IL-6 Production in LPS-Stimulated RAW264.7 Cells. The inhibitory effect of the ethanolic extract of C. garettiana on proinflammatory cytokine, including TNF- $\alpha$ and IL-6, was determined. The results showed no toxicity on RAW264.7 cells where the percentage of cell viability was higher than $70 \%$ at all concentrations, as shown in Figure 2(a). C. garettiana extract could not inhibit TNF- $\alpha$ production, but it significantly inhibited IL- 6 production at all concentrations. IL-6 production was lower than $60 \mathrm{pg} / \mathrm{mL}$ after treatment with $C$. garettiana extract at the concentrations of 25,50 , and $100 \mu \mathrm{g} / \mathrm{mL}$, while the extract showed low inhibitory action on IL- 6 at the concentration of $12.5 \mu \mathrm{g} / \mathrm{mL}$. However, prednisolone that was used as a positive control significantly inhibited TNF- $\alpha$ and IL-6 production at a concentration of $0.1-10 \mu \mathrm{g} / \mathrm{mL}$, as shown in Figure 3. TNF- $\alpha$ and IL- 6 are important cytokines in pathogenic infection. TNF- $\alpha$ related host defends it against bacteria and induces fever, while IL- 6 induces differentiation of B cells, protects the mucosal, and induces fever $[24,25]$. Our work is the first report describing the effect of C. garettiana extract on macrophage cytokines. C. garettiana extract significantly reduced IL-6 production but did not influence TNF- $\alpha$ secretion. IL- 6 is known to be a proinflammatory and anti-inflammatory cytokine. The increase of IL- 6 expression suppresses inflammation and inhibits IL-1 and TNF- $\alpha$ production [26]. The lack of suppression of TNF- $\alpha$ production may be related to the decrease of IL-6 production during treatment with $C$. garettiana extract.

3.4. Determination of Piceatannol and Resveratrol in the Ethanolic Extract of C. garettiana by HPLC. The ethanolic extract of C. garettiana was analyzed for its chemical constituents. The major component found was piceatannol with the retention time of about $22.2 \mathrm{~min}$ with the average content of $426.31 \pm 17.62 \mathrm{mg} / \mathrm{g}$ of dried extract. Resveratrol was another compound found in the ethanolic extract, identified at about $26.3 \mathrm{~min}$ with the content of $3.79 \pm 0.30 \mathrm{mg} / \mathrm{g}$ of dried extract, as shown in Figure 4 . The chemical structure of piceatannol and resveratrol is shown in Figure 5 .

Piceatannol and resveratrol were investigated for their antibacterial activity. Piceatannol was effective against $S$. aureus, MRSA, and S. epidermidis with MIC value of $250 \mu \mathrm{g} / \mathrm{mL}$, while it showed a less potent activity against $E$. coli, Salmonella Typhi, Salmonella Typhimurium, K. pneumoniae, and S. dysenteriae (MIC values: $500-1,000 \mu \mathrm{g} / \mathrm{mL}$ ). On the other hand, resveratrol showed no inhibition against any test bacteria, as shown in Table 2.

The major component of C. garettiana was piceatannol that showed an antibacterial activity against nine species of bacteria. The extract contained about $42.6 \% \mathrm{w} / \mathrm{w}$ of piceatannol followed by resveratrol. Piceatannol and resveratrol have been reported to possess an antibacterial activity against Salmonella Infantis, Listeria monocytogenes, and Candida tropicalis [27]. Our study also showed that piceatannol could kill two species of Salmonella, but resveratrol showed no antibacterial activity. Piceatannol is a hydroxylated analog of resveratrol that contains the hydroxyl group at $3^{\prime}$ carbon atom [9]. Some reports showed piceatannol to have better radical scavenging activity than resveratrol because of the hydrogen bond formation of the orthodihydroxy groups [28]. For 
TABLE 1: The MIC and MBC values of C. garettiana extract, norfloxacin, and vancomycin against nine species of bacteria.

\begin{tabular}{|c|c|c|c|c|c|c|c|}
\hline \multirow{2}{*}{ Bacteria } & \multicolumn{3}{|c|}{ C. garettiana extract } & \multicolumn{2}{|c|}{ Norfloxacin } & \multicolumn{2}{|c|}{ Vancomycin } \\
\hline & $\operatorname{MIC}(\mu \mathrm{g} / \mathrm{mL})$ & $\operatorname{MBC}(\mu \mathrm{g} / \mathrm{mL})$ & $\mathrm{MBC} / \mathrm{MIC}$ & $\mathrm{MIC}(\mu \mathrm{g} / \mathrm{mL})$ & $\operatorname{MBC}(\mu \mathrm{g} / \mathrm{mL})$ & $\operatorname{MIC}(\mu \mathrm{g} / \mathrm{mL})$ & $\operatorname{MBC}(\mu \mathrm{g} / \mathrm{mL})$ \\
\hline S. aureus & 312.5 & 625 & 2 & 1.5625 & 25 & NT & NT \\
\hline MRSA & 312.5 & 625 & 2 & $>200$ & $>200$ & 1.5625 & 12.5 \\
\hline S. epidermidis & 312.5 & 312.5 & 1 & 0.7813 & 1.5625 & NT & NT \\
\hline E. coli & 1.250 & 1.250 & 1 & 0.0122 & 0.024 & NT & NT \\
\hline K. pneumoniae & 2.500 & 2.500 & 1 & 1.5625 & 6.25 & NT & NT \\
\hline P. aeruginosa & 2.500 & 2.500 & 1 & 0.78 & 12.5 & NT & NT \\
\hline S. dysenteriae & 625 & 625 & 1 & 0.024 & 0.048 & NT & NT \\
\hline Salmonella Typhi & 625 & 625 & 1 & 1.5625 & 200 & NT & NT \\
\hline Salmonella Typhimurium & 625 & 625 & 1 & 0.3906 & 0.7813 & NT & NT \\
\hline
\end{tabular}

${ }^{*} \mathrm{NT}=$ not test.

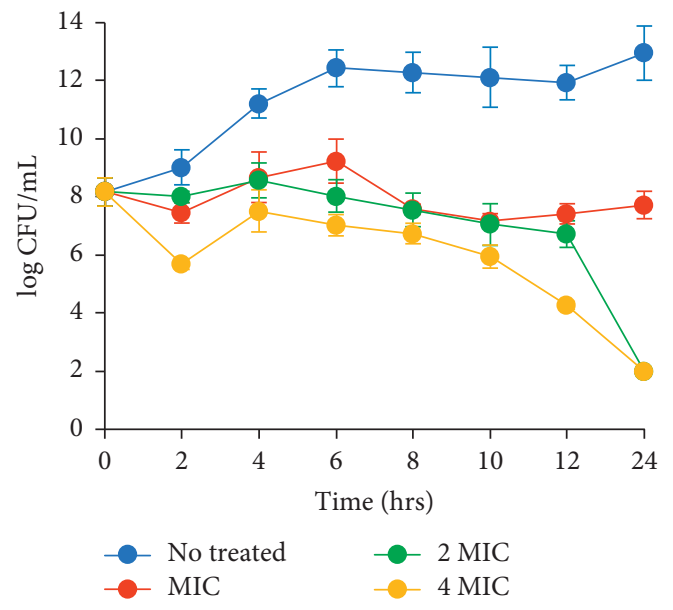

(a)

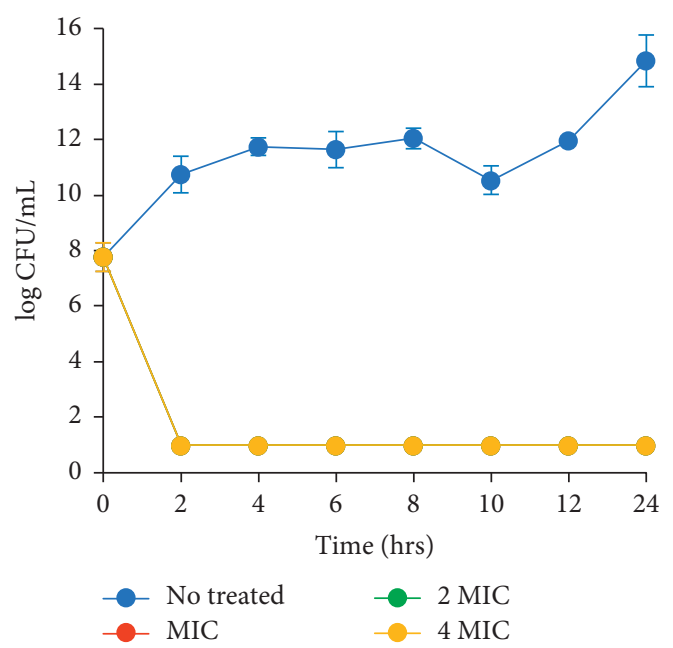

(c)

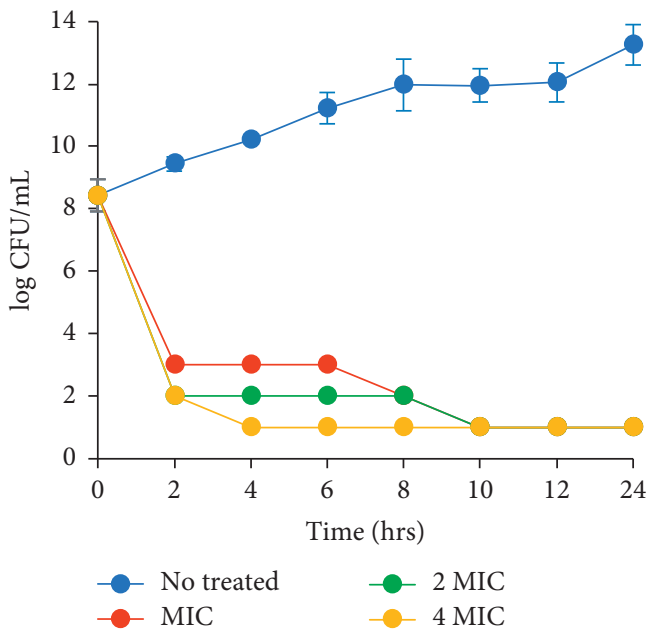

(b)

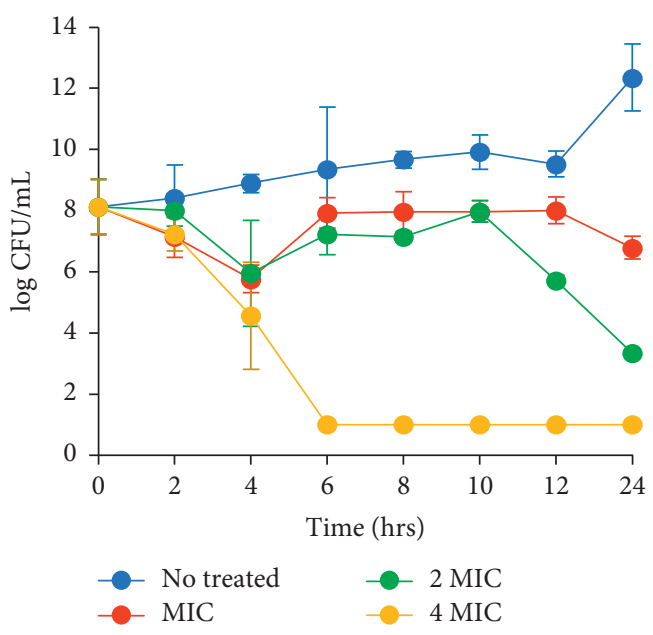

(d)

Figure 1: Continued. 

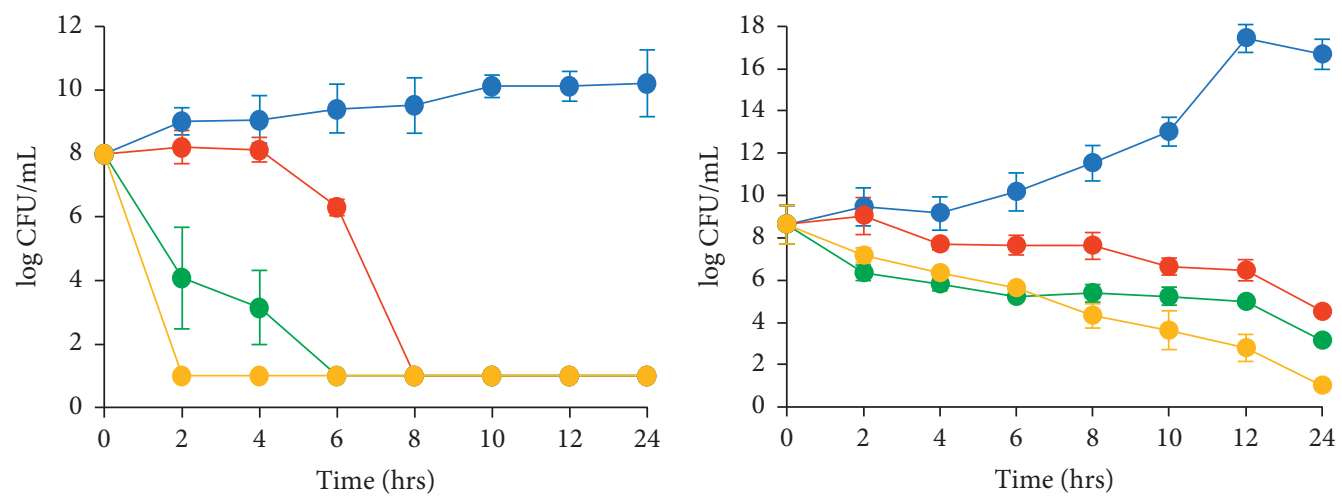

$\begin{array}{ll}- \text { No treated } & -2 \text { MIC } \\ - \text { MIC } & -\end{array}$

(e)

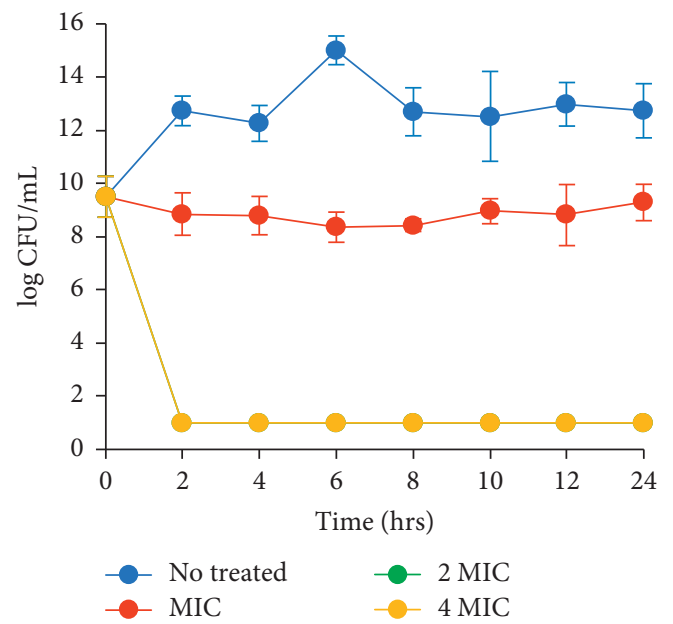

(g)

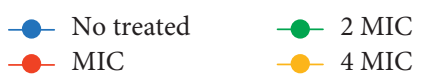

(f)

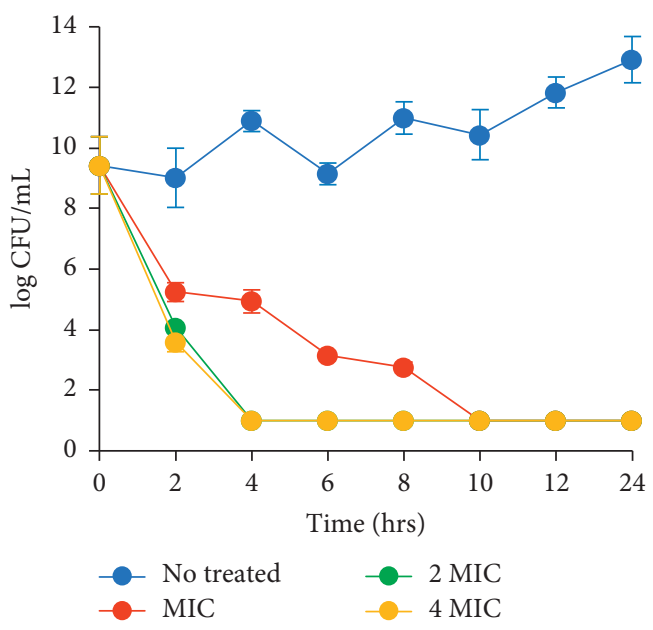

(h)

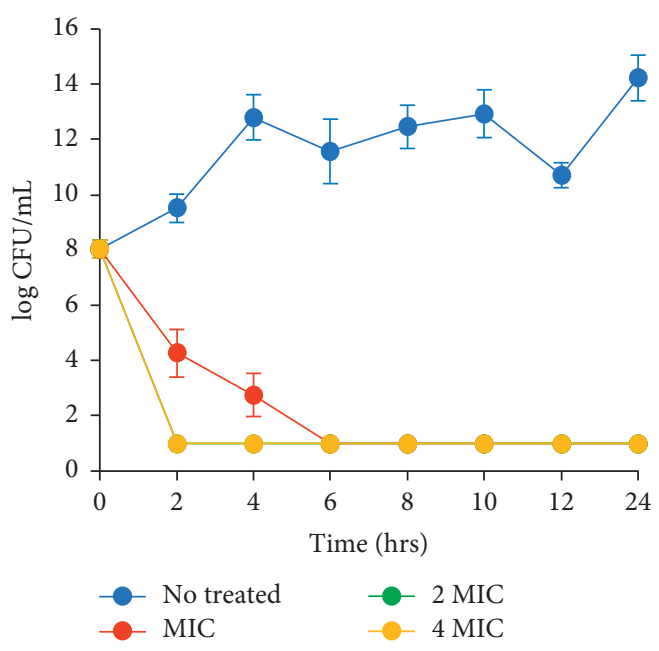

(i)

Figure 1: Time-kill plots of C. garettiana extract against S. aureus (a), E. coli (b), P. aeruginosa (c), MRSA (d), S. dysenteriae (e), S. epidermidis (f), Salmonella Typhimurium (g), Salmonella Typhi (h), and K. pneumoniae (i). 


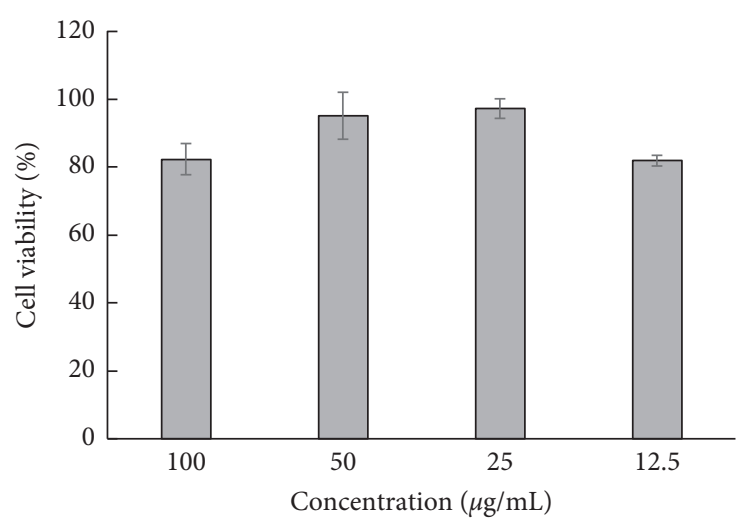

(a)

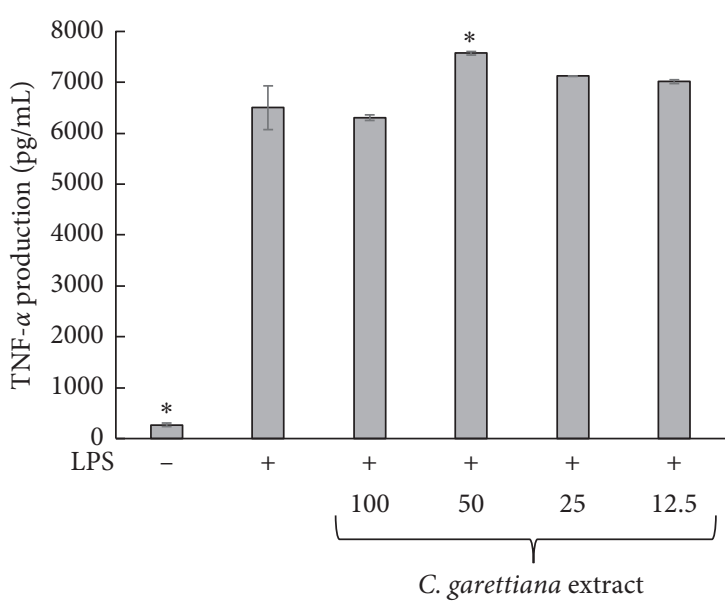

(b)

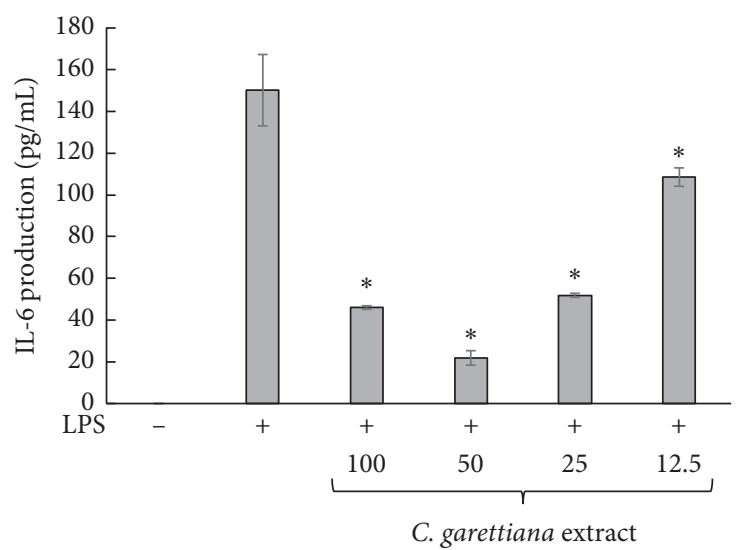

(c)

Figure 2: Effect of C. garettiana extract on RAW264.7 cell viability (a), TNF- $\alpha$ production (b), and IL-6 production (c). ${ }^{*} p<0.05$ when compared with LPS-stimulated condition.

antibacterial activity, piceatannol showed activity against $P$. aeruginosa while resveratrol can inhibit $S$. aureus with the MIC values of 128 and $512 \mu \mathrm{g} / \mathrm{mL}$, respectively [29]. Another report showed that piceatannol inhibits $S$. aureus DSMZ6148 with an average MIC of 283 and $383 \mu \mathrm{g} / \mathrm{mL}$ [30]. In our study, piceatannol showed better antibacterial activity than resveratrol. One possibility is that the hydroxyl group may affect bacterial membrane, so piceatannol which has the hydroxyl group at $3^{\prime}$ carbon atom could inhibit bacterial growth better than resveratrol. Resveratrol has been reported to possess antibacterial activity against Gram-negative and Gram-positive bacteria [31]. However, time-kill kinetic of resveratrol displayed bacteriostatic activity towards $S$. aureus [32]. On the other hand, our results showed that resveratrol had no antibacterial activity against all test bacteria. Some reports indicated that a concentration of resveratrol higher than $60 \mu \mathrm{g} / \mathrm{mL}$ reduced the inhibitory effect of resveratrol on growth of mycelia in Botrytis cinereal [33]. In this research, resveratrol was prepared at a high concentration that may lead to poor solubility and weak antibacterial activity.

In the determination of anti-inflammatory activity, the results showed that piceatannol was toxic on RAW264.7 cells at a concentration of $100 \mu \mathrm{g} / \mathrm{mL}$, with the cell viability lower than $70 \%$, as shown in Figure 6(a). The inhibitory effect of piceatannol on IL- 6 and TNF- $\alpha$ production was further investigated at concentrations of $6.25-50 \mu \mathrm{g} / \mathrm{mL}$. It showed no inhibitory effect on TNF- $\alpha$ production, similar to C. garettiana extract (Figure 6(b)). However, IL-6 production was lower than $50 \%$ of maximum when LPS-stimulated RAW264.7 was treated with piceatannol at the concentrations of $12.5-50 \mu \mathrm{g} / \mathrm{mL}$. The IL- 6 production increased with $6.25 \mu \mathrm{g} / \mathrm{ml}$ of piceatannol when compared with other concentrations (Figure 6(c)).

Resveratrol was toxic to RAW264.7 cells at the concentrations of 50 and $100 \mu \mathrm{g} / \mathrm{mL}$; therefore, its inhibitory effect on TNF- $\alpha$ and IL- 6 was determined at $6.25-25 \mu \mathrm{g} / \mathrm{mL}$, as shown in Figure 7(a). Results showed that TNF- $\alpha$ production was not inhibited by resveratrol at all concentrations (Figure 7(b)), but it completely inhibited IL-6 production from RAW264.7 cells at 12.5 and $25 \mu \mathrm{g} / \mathrm{mL}$. At $6.25 \mu \mathrm{g} / \mathrm{mL}$, resveratrol strongly inhibited the IL-6 production but did not completely inhibit its expression, as shown in Figure 7(c).

Piceatannol and resveratrol were chemical constituents found in C. garettiana. Piceatannol has been reported to inhibit TNF- $\alpha$ and IL- 6 production at the concentration of 


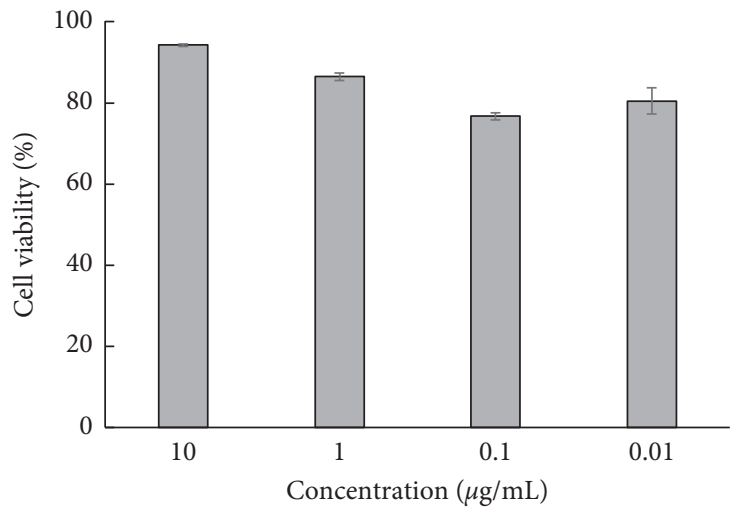

(a)

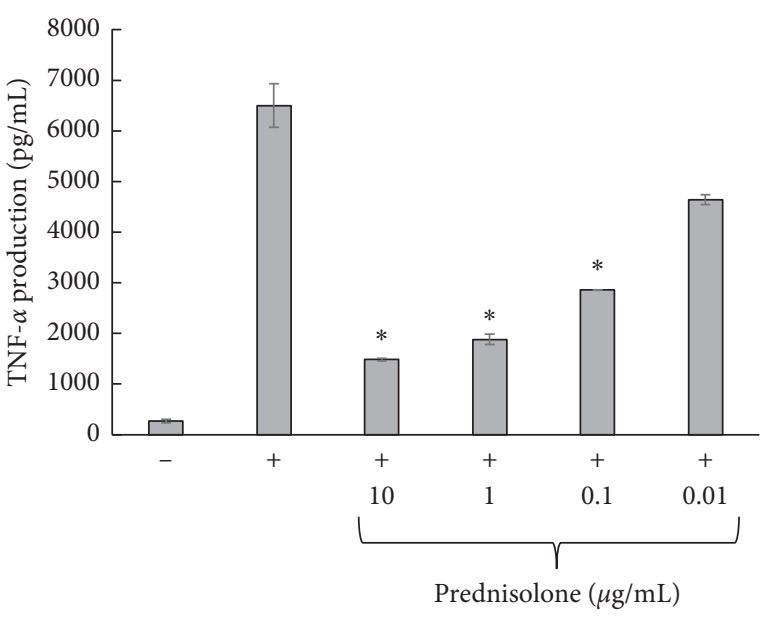

(b)

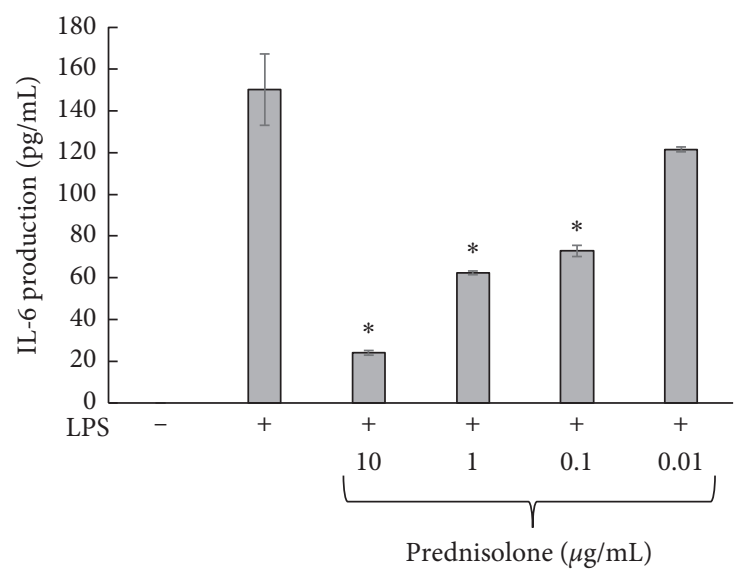

(c)

FIGURE 3: Effect of prednisolone on RAW264.7 cell viability (a), TNF- $\alpha$ production (b), and IL-6 production (c). ${ }^{*} p<0.05$ when compared with LPS-stimulated condition.

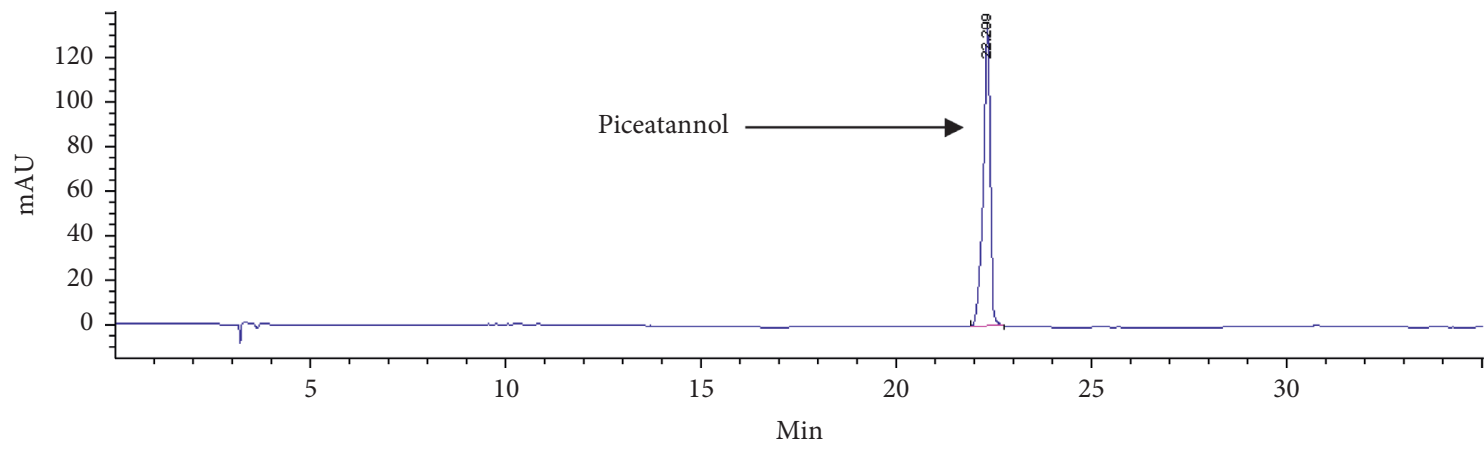

(a)

Figure 4: Continued. 


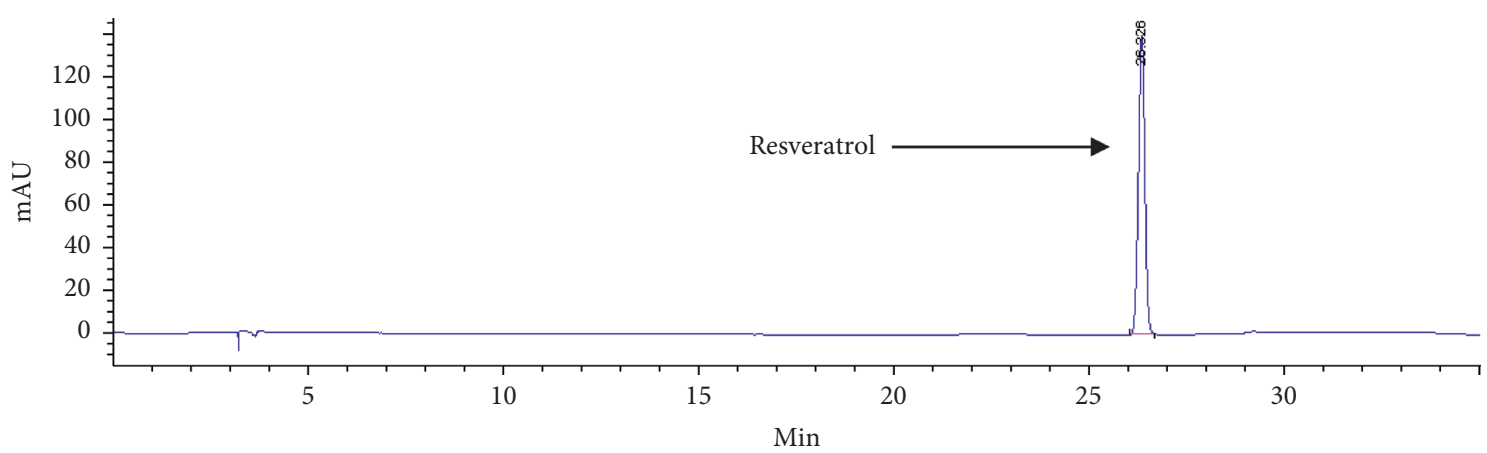

(b)

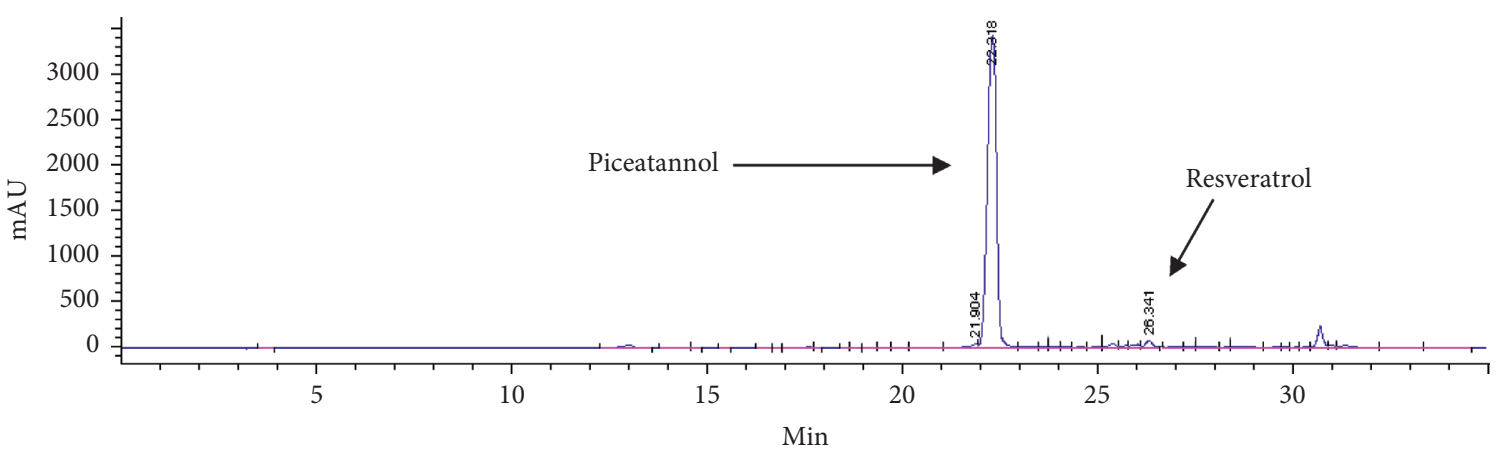

(c)

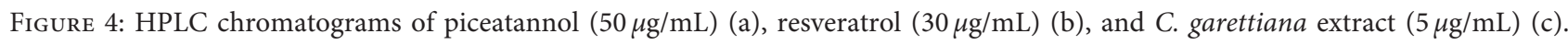<smiles>Oc1cc(O)cc(/C=C/c2ccc(O)c(O)c2)c1</smiles>

(a)<smiles>Oc1ccc(/C=C/c2cc(O)cc(O)c2)cc1</smiles>

(b)

Figure 5: Chemical structures of piceatannol (a) and resveratrol (b).

TABLE 2: MIC and MBC values of piceatannol and resveratrol against nine species of bacteria.

\begin{tabular}{|c|c|c|c|c|c|}
\hline \multirow{2}{*}{ Bacteria } & \multicolumn{3}{|c|}{ Piceatannol } & \multicolumn{2}{|c|}{ Resveratrol } \\
\hline & $\operatorname{MIC}(\mu \mathrm{g} / \mathrm{mL})$ & $\mathrm{MBC}(\mu \mathrm{g} / \mathrm{mL})$ & $\mathrm{MBC} / \mathrm{MIC}$ & $\operatorname{MIC}(\mu \mathrm{g} / \mathrm{mL})$ & $\operatorname{MBC}(\mu \mathrm{g} / \mathrm{mL})$ \\
\hline S. aureus & 250 & 500 & 2 & $>1.000$ & $>1.000$ \\
\hline MRSA & 250 & 500 & 2 & $>1.000$ & $>1.000$ \\
\hline S. epidermidis & 250 & 250 & 1 & $>1.000$ & $>1.000$ \\
\hline E. coli & 500 & 500 & 1 & $>1.000$ & $>1.000$ \\
\hline K. pneumoniae & 1.000 & 1.000 & 1 & $>1.000$ & $>1.000$ \\
\hline P. aeruginosa & $>1.000$ & $>1.000$ & - & $>1.000$ & $>1.000$ \\
\hline S. dysenteriae & 500 & 500 & 1 & $>1.000$ & $>1.000$ \\
\hline Salmonella Typhi & 500 & 500 & 1 & $>1.000$ & $>1.000$ \\
\hline Salmonella Typhimurium & 500 & 500 & 1 & $>1.000$ & $>1.000$ \\
\hline
\end{tabular}

10-30 $\mu \mathrm{M}$, while resveratrol could inhibit only TNF- $\alpha$ production in LPS-stimulated RAW264.7 cells [34]. Our investigation differs from the previous report in that it showed piceatannol and resveratrol had an inhibition effect on IL- 6 but not on TNF- $\alpha$. Other reports showed that piceatannol decreased mRNA expression and protein level of IL-6 and MCP-1in 3T3-L1 adipocytes cells via blocking of $\mathrm{I} \kappa \mathrm{B} \alpha$ phosphorylation and NF- $\kappa \mathrm{B}$ activation, while 


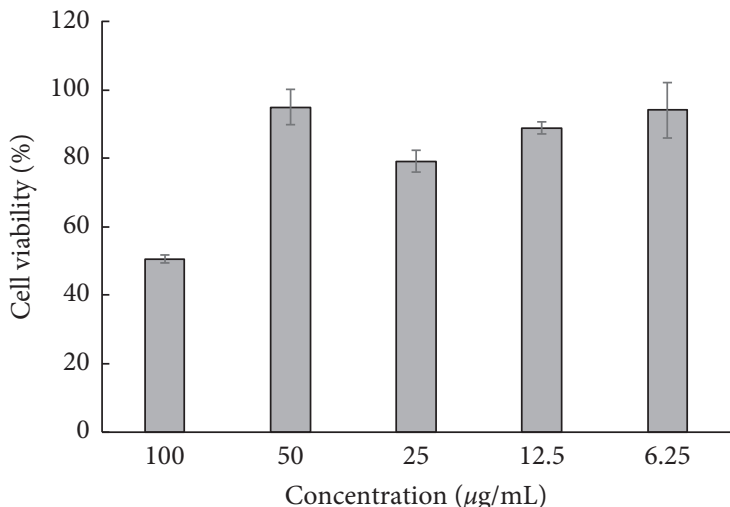

(a)

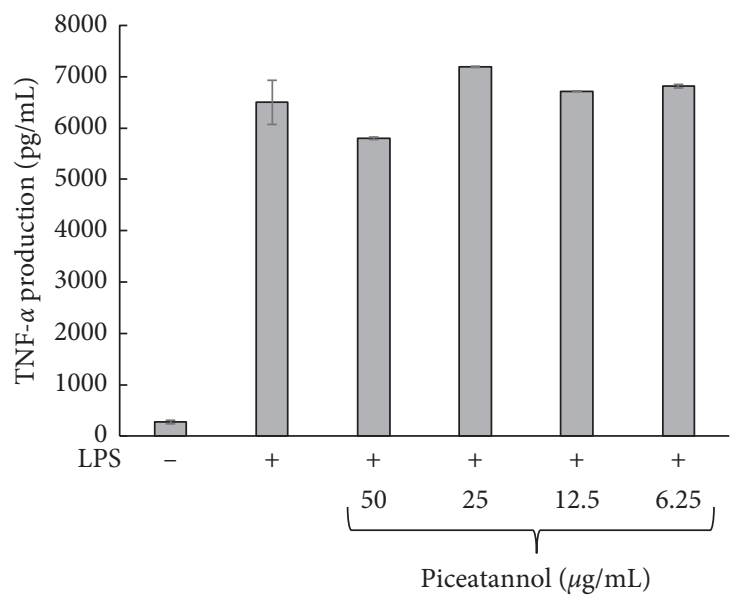

(b)

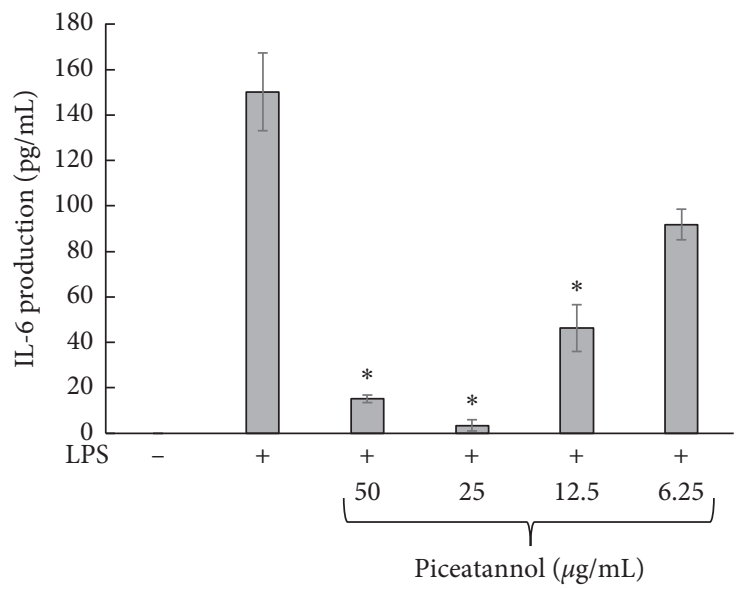

(c)

FIGURE 6: Effect of piceatannol on RAW264.7 cell viability (a), TNF- $\alpha$ production (b), and IL-6 production (c); ${ }^{*} p<0.05$ when compared with LPS-stimulated condition.

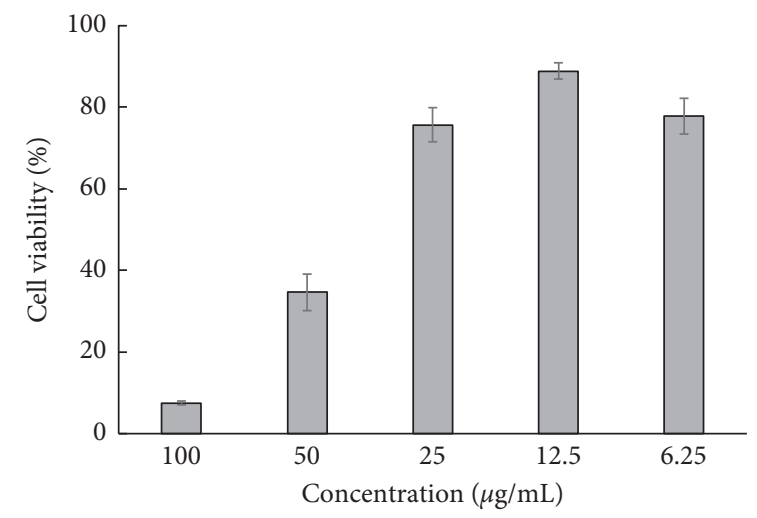

(a)

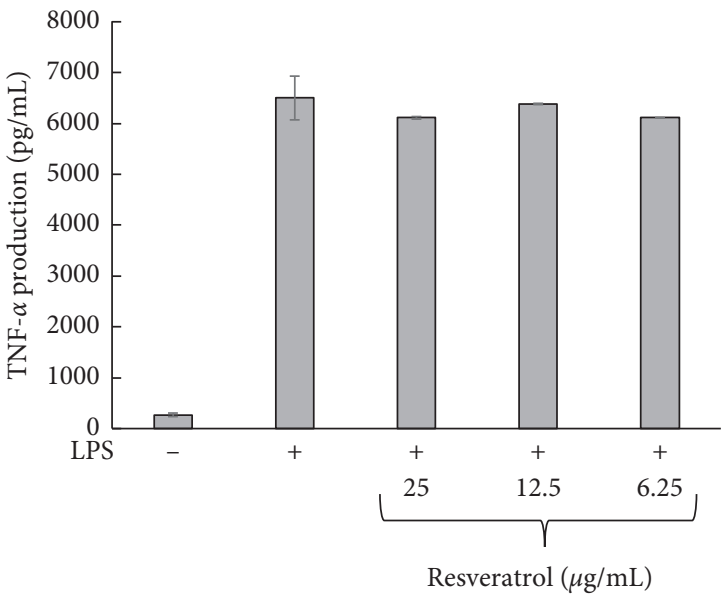

(b)

Figure 7: Continued. 


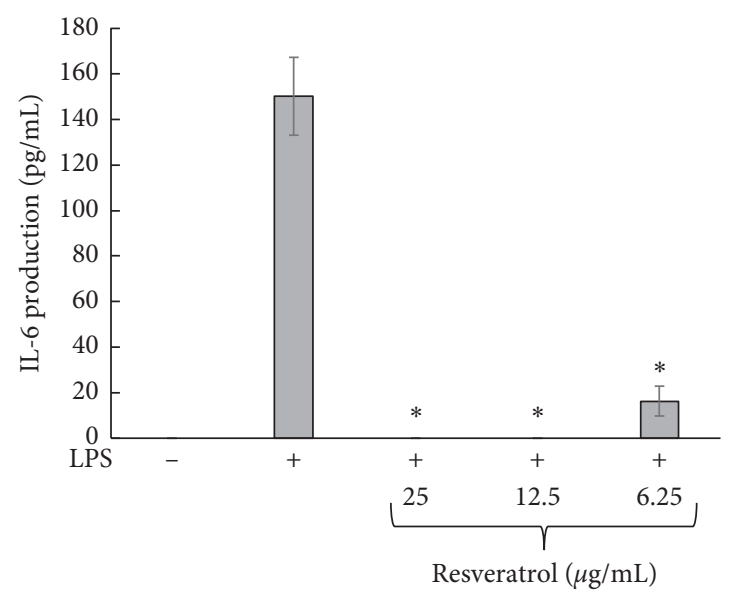

(c)

FiguRE 7: Effect of resveratrol on RAW264.7 cell viability (a), TNF- $\alpha$ production (b), and IL-6 production (c); ${ }^{*} p<0.05$ when compared with LPS-stimulated condition.

resveratrol also inhibited cytokines and chemokine secretion such as IL- $1 \alpha$, IL- $1 \beta$, IL-6, TNF- $\alpha$, CCL4/MIP- $1 \beta$, and CCL5/ RANTES in LPS-activated macrophages $[35,36]$. On the other hand, our study revealed that resveratrol inhibits only the level of IL-6 production. Similarly, diphlorethohydroxycarmalol that was isolated from a brown alga showed a strong inhibition effect on IL-6 but not TNF- $\alpha$ via suppressing Jak2-STAT5 activation and SOCS1 augmentation [37]. Therefore, resveratrol may suppress the specific mechanism in IL-6 production. However, the main active compound of C. garettiana was piceatannol that was found to be about $43 \% \mathrm{w} / \mathrm{w}$ of dried extract. Piceatannol and C. garettiana extract showed similar antibacterial and anti-inflammatory activities. Other active components in C. garettiana, for example, resveratrol, may also affect the biological activity of this plant.

\section{Conclusions}

In conclusion, C. garettiana was a broad-spectrum bactericidal agent. It contained major bioactive compounds which included piceatannol that showed anti-inflammatory and antibacterial activities against Gram-negative and Grampositive bacteria. A study on the use of C. garettiana extract in combination with antibiotics against serious bacterial infections may prove useful. Furthermore, C. garettiana showed a high potential for inhibition of MRSA, so its effect on beta-lactamase and other antibiotic-resistant strains of bacteria should be assessed in the future.

\section{Data Availability}

The datasets used and/or analyzed during the current study are available from the corresponding author on reasonable request.

\section{Conflicts of Interest}

The authors have no financial or personal conflicts of interest to declare.

\section{Acknowledgments}

This research was supported by the Centre of Excellence in Applied Thai Traditional Medicine Research, Faculty of Medicine, Thammasat University, and Bualuang ASEAN Chair Professorship.

\section{References}

[1] P. D. Thomson and D. J. Smith, "What is infection?" The American Journal of Surgery, vol. 167, no. 1, pp. S7-S11, 1994.

[2] L. Chen, H. Deng, H. Cui et al., "Inflammatory responses and inflammation-associated diseases in organs," Oncotarget, vol. 9, no. 6, pp. 7204-7218, 2017.

[3] S. Leekha, C. L. Terrell, and R. S. Edson, "General principles of antimicrobial therapy," Mayo Clinic Proceedings, vol. 86, no. 2, pp. 156-167, 2011.

[4] C. L. Ventola, "The antibiotic resistance crisis: part 1: causes and threats," P \& T: A Peer-Reviewed Journal for Formulary Management, vol. 40, no. 4, pp. 277-283, 2015.

[5] C. L. Ventola, "The antibiotic resistance crisis: part 2: management strategies and new agents," $P$ \& T: A Peer-Reviewed Journal for Formulary Management, vol. 40, no. 5, pp. 344352, 2015.

[6] M. J. Cheesman, A. Ilanko, B. Blonk, and I. E. Cock, "Developing new antimicrobial therapies: are synergistic combinations of plant extracts/compounds with conventional antibiotics the solution?" Pharmacognosy Reviews, vol. 11, no. 22, pp. 57-72, 2017.

[7] S. Tewtrakul, S. Subhadhirasakul, and P. Rattanasuwan, "HIV1 protease inhibitory effects of some selected plants in Caesalpiniaceae and Papilionaceae families," Songklanakarin Journal of Science and Technology, vol. 25, no. 4, pp. 509-514, 2003.

[8] S. Tewtrakul, S. Subhadhirasakul, P. Rattanasuwan, and J. Puripattanvong, "HIV-1 protease inhibitory substances from Cassia garettiana," Songklanakarin Journal of Science and Technology, vol. 29, no. 1, pp. 145-149, 2007.

[9] A. Kukreja, N. Wadhwa, and A. Tiwari, "Therapeutic role of resveratrol and piceatannol in disease prevention," Journal of Blood Disorders \& Transfusion, vol. 5, no. 9, pp. 1-6, 2014. 
[10] M. A. Prateeksha, M. A. Yusuf, B. N. Singh et al., "Chrysophanol: a natural anthraquinone with multifaceted biotherapeutic potential," Biomolecules, vol. 9, no. 2, p. 68, 2019.

[11] Y. J. Cao, Z. J. Pu, Y. P. Tang et al., "Advances in bio-active constituents, pharmacology and clinical applications of rhubarb," Chinese Medicine, vol. 12, no. 36, 2017.

[12] S. D. Sarker, L. Nahar, and Y. Kumarasamy, "Microtitre platebased antibacterial assay incorporating resazurin as an indicator of cell growth, and its application in the in vitro antibacterial screening of phytochemicals," Methods, vol. 42, no. 4, pp. 321-324, 2007.

[13] T. Appiah, Y. D. Boakye, and C. Agyare, "Antimicrobial activities and time-kill kinetics of extracts of selected Ghanaian mushrooms," Evid Based Complement Alternat Med, vol. 2017, Article ID 4534350, 16 pages, 2017.

[14] J. O’Brien, I. Wilson, T. Orton, and F. Pognan, "Investigation of the Alamar Blue (resazurin) fluorescent dye for the assessment of mammalian cell cytotoxicity," European Journal of Biochemistry, vol. 267, no. 17, pp. 5421-5426, 2000.

[15] C. Calhoun and G. A. Hall, Antibiotics, StatPearls, Treasure Island, FL, USA, 2020.

[16] B. Aslam, W. Wang, M. I. Arshad et al., "Antibiotic resistance: a rundown of a global crisis," Infection and Drug Resistance, vol. 11, pp. 1645-1658, 2018.

[17] M. G. Moloney, "Natural products as a source for novel antibiotics," Trends in Pharmacological Sciences, vol. 37, no. 8, pp. 689-701, 2016.

[18] M. E. Levison, "Pharmacodynamics of antimicrobial drugs," Infectious Disease Clinics of North America, vol. 18, no. 3, pp. 451-465, 2004.

[19] S. M. Seyyednejad, H. Motamedi, M. Vafei, and A. Bakhtiari, "The antibacterial activity of Cassia fistula organic extracts," Jundishapur Journal of Microbiology, vol. 7, no. 1, Article ID e8921, 2014.

[20] T. Promgool, O. Pancharoen, and S. Deachathai, "Antibacterial and antioxidative compounds from Cassia alata Linn," Songklanakarin Journal of Science and Technology, vol. 36, no. 4, pp. 459-463, 2014.

[21] A. Belley, E. Neesham-Grenon, F. F. Arhin, G. A. McKay, T. R. Parr Jr., and G. Moeck, "Assessment by time-kill methodology of the synergistic effects of oritavancin in combination with other antimicrobial agents against Staphylococcus aureus," Antimicrobial Agents and Chemotherapy, vol. 52, no. 10, pp. 3820-3822, 2008.

[22] R. J. Melander, D. V. Zurawski, and C. Melander, "Narrowspectrum antibacterial agents," Medchemcomm, vol. 9, no. 1, pp. 12-21, 2018.

[23] P. D. Stapleton and P. W. Taylor, "Methicillin resistance in Staphylococcus aureus: mechanisms and modulation," Science Progress, vol. 85, no. 1, pp. 57-72, 2002.

[24] S. M. Dann, M. E. Spehlmann, D. C. Hammond et al., "IL-6Dependent mucosal protection prevents establishment of a microbial niche for attaching/effacing lesion-forming enteric bacterial pathogens," The Journal of Immunology, vol. 180, no. 10, pp. 6816-6826, 2008.

[25] G. A. Duque and A. Descoteaux, "Macrophage cytokines: involvement in inaate immunity and infectious diseases," Frontiers in Immunology, vol. 5, pp. 1-12, 2014.

[26] H. Tilg, E. Trehu, M. Atkins, C. Dinarello, and J. Mier, "Interleukin-6 (IL-6) as an anti-inflammatory cytokine: induction of circulating IL-1 receptor antagonist and soluble tumor necrosis factor receptor p55," Blood, vol. 83, no. 1, pp. 113-118, 1994.

[27] C. Plumed-Ferrer, K. Väkeväinen, H. Komulainen et al., "The antimicrobial effects of wood-associated polyphenols on food pathogens and spoilage organisms," International Journal of Food Microbiology, vol. 164, no. 1, pp. 99-107, 2013.

[28] Y. Sueishi, R. Nii, and N. Kakizaki, "Resveratrol analogues like piceatannol are potent antioxidants as quantitatively demonstrated through the high scavenging ability against reactive oxygen species and methyl radical," Bioorganic \& Medicinal Chemistry Letters, vol. 27, no. 23, pp. 5203-5206, 2017.

[29] L. M. Mattio, S. Dallavalle, L. Musso et al., "Antimicrobial activity of resveratrol-derived monomers and dimers against foodborne pathogens," Scientific Reports, vol. 9, no. 1, Article ID 19525, 2019.

[30] N. Guldas, T. Uysal, H. Ellidokuz, and Y. Basbinar, "Antimicrobial effect of piceatannol, a resveratrol metabolite, on Staphylococcus aureus," The Journal of Basic and Clinical Health Sciences, vol. 3, pp. 184-187, 2019.

[31] D. S. L. Ma, L. T. Tan, K. G. Chan et al., "Resveratrol-potential antibacterial agent against foodborne pathogens," Frontiers in Pharmacology, vol. 9, p. 102, 2018.

[32] L. Zhang, F. Dai, P.-L. Sheng, Z.-Q. Chen, Q.-P. Xu, and Y.-Q. Guo, "Resveratrol analogue 3,4,4'-trihydroxy-transstilbene induces apoptosis and autophagy in human nonsmall-cell lung cancer cells in vitro," Acta Pharmacologica Sinica, vol. 36, no. 10, pp. 1256-1265, 2015.

[33] P. Jeandet, A.-C. Douillet-Breuil, R. Bessis, S. Debord, M. Sbaghi, and M. Adrian, "Phytoalexins from the vitaceae: biosynthesis, phytoalexin gene expression in transgenic plants, antifungal activity, and metabolism," Journal of Agricultural and Food Chemistry, vol. 50, no. 10, pp. 2731-2741, 2002.

[34] T. Yamamoto, Y. Li, Y. Hanafusa et al., "Piceatannol exhibits anti-inflammatory effects on macrophages interacting with adipocytes," Food Science \& Nutrition, vol. 5, no. 1, pp. 76-85, 2016.

[35] Y. Li, P. Yang, Q. Chang et al., "Inhibitory effect of piceatannol on TNF- $\alpha$-mediated inflammation and insulin resistance in 3T3-L1 adipocytes," Journal of Agricultural and Food Chemistry, vol. 65, no. 23, pp. 4634-4641, 2017.

[36] J. Schwager, N. Richard, F. Widmer, and D. Raederstorff, "Resveratrol distinctively modulates the inflammatory profiles of immune and endothelial cells," BMC Complementary and Alternative Medicine, vol. 17, no. 1, pp. 1-12, 2017.

[37] N.-J. Kang, S.-C. Han, G.-J. Kang et al., "Diphlorethohydroxycarmalol inhibits interleukin- 6 production by regulating NF- $\kappa$ B, STAT5 and SOCS1 in lipopolysaccharide-stimulated RAW264.7 cells," Marine Drugs, vol. 13, no. 4, pp. 2141-2157, 2015. 